\title{
DYNAMICS OF TRANSPIRATION PROCESS IN TRANSPLANTING INTO THE GROUND THE POMEGRANATE (Punica granatum L.) SEEDLINGS GROWN UNDER IN VITRO CONDITIONS
}

\author{
Ergasheva F.Sh., Abdurasulova M.A., Usmanov M.R., Goipova S.A. and Abdurashitov S.S. \\ Gulistan State University, Gulistan City, Republic of Uzbekistan
}

https://doi.org/10.35410/IJAEB.2022.5705

\begin{abstract}
In vitro grown pomegranate seedlings were found to have a low specific leaf mass $(\mathrm{g} / \mathrm{dm} 2)$ in the first day (1 day), which was supposed to be associated with high water content in the leaf during the initial period of adaptation to natural soil conditions. As an object of the study "Qora qayim", "Qizil anor", "Oq dona (Tuyatish)", and "Achchiq dona" local varieties of pomegranate were selected which grow in Sirdarya region of the Republic of Uzbekistan. It was also found that the transpiration intensity was relatively high in the early stages of the adaptation period when transplanting a plant grown under in vitro condition into a non-sterile soil environment, as well as a decrease in water content in the leaves, i.e. a high water deficit value was observed, and accordingly, it is recommended to increase the humidity level in the atmospheric environment around the plant to $90-95 \%$ and then gradually reduce it to $50 \%$ in order to ensure optimal adaptation mechanisms of the plant to soil conditions.
\end{abstract}

Keywords: Punica granatum L,pomegranate, in vitro, transpiration, adaptation, microclonal propagation.

\section{INTRODUCTION}

Efficient use of arable land is of strategic importance in the cultivation of agricultural crops. Due to the salinization and degradation of arable lands, the selection and cultivation of plants of economic and social significance in accordance with the conditions is one of the most pressing issues for science and industry[3]. Therefore, microclonal propagation of pomegranate under in vitro condition and obtaining pathogen-free seedlings are of great importance.

Today, many major research centers around the world pay special attention to the cultivation of pomegranates in connection with the increase in agricultural crop yields. The proper choice of varieties of pomegranate suitable for ecological climatic conditions allows high yields of pomegranate and its wide use in the food industry[19]. Accordingly, microclonal propagation of local pomegranate varieties under in vitro condition is important in terms of relevance.

At present, in the Republic of Uzbekistan a special attention is paid to the implementation of scientific and innovative achievements in the production of ecologically pure products from plants. However, enough research and studies haven't been done in the country on the creation of pomegranate varieties resistant to local climatic and soil conditions, in turn, theoretical and practical research in this area is considered most relevant. 
Pomegranate (Punica granatum L.) is a subtropical plant species belonging to the family Punicaceae Horan, consisting of 1 genus (Punica L.) that includes 2 species (P. granatum L. and $P$. protopunica Balf.)[12]. Pomegranate leaves are elliptical, narrow, located opposite to each other at the base. In different geographical and climatic regions, pomegranate fruit growing conditions, growing period and fruit ripening times differ significantly. For example, in the Northern Hemisphere, pomegranates ripen in September-October [8], while in the Southern Hemisphere (South Africa, etc.) they ripen in March-May [9].

Pomegranate is propagated mainly vegetatively by cuttings, it is a drought- and frost -resistant ($15-17^{\circ} \mathrm{C}$ ) plant that loves moist. The fruit of the pomegranate has long been mentioned since the ancient times as a source of happiness in the religion Buddhism, and a fruit of paradise in Islam. In the ancient East and China, it was valued as a symbol of prosperity and fertility [15].

The aim of the study was to make a comparative analysis of the dry matter and water content of the leaves of local pomegranate varieties and to analyze the dynamics of their change over time intervals.

\section{MATERIALS AND METHODS}

Transpiration intensity is an integral indicator of water regime in plants and was determined using a standard method in the study $[5 ; 7 ; 14]$. The transpiration rate was calculated using the following formula [10]:

$$
T=\frac{m_{i}-m}{t \times\left(\frac{m_{i}}{1000}\right)}
$$

Where:

$T$ is transpiration rate; $m_{i}$ is initial weight of leaf, $(\mathrm{gm}) ; m$ is leaf weight after passing and $t$ is time (min.).

In the studies, transpiration intensity in pomegranate leaf was determined using a standard method. The cut plant leaf was weighed every 5 minutes, the intensity of transpiration was expressed as the amount of water evaporating from $1 \mathrm{~cm} 2$ of leaf surface during 1 hour. Transpiration intensity was calculated by the following formula $[3,6]$.

$$
T_{\text {intensity }}=\frac{n \times 12}{S}
$$

$n$ is the amount of water evaporating for 5 min.from leaf surface $(\mathrm{mg}) ; 12$ is the coefficient of conversion of minutes into hours $\left(\frac{60}{5}\right)=12 ; S$ is the surface area of leaf $\left(\mathrm{cm}^{2}\right)$. 
Transpiration is an important process associated with the water regime in plant metabolism and is an integral indicator of the water regime [8]. In transpiration, $90 \%$ of the water absorbed from the soil layer by the plant root evaporates through the leaves, $582 \mathrm{cal} / \mathrm{g}$ of heat is released from the plant at $+20^{\circ} \mathrm{C}$, and the body maintains optimal thermoregulation. The transport of substances through the conduction system in the plant is activated during transpiration. The outer surface of the pomegranate leaf is covered with a layer of cuticle, on the surface of the leaf there are 1-60 stomata with a diameter of $\sim 3-12 \mu \mathrm{m}$, relative to the surface of $1 \mathrm{~cm}^{2}$ [5].

Determination of water content in pomegranate leaves was performed using a standard method [12]. In this case, the surface of the leaf was washed with distilled water, wiped with a sterilized paper napkin and weighed in a dry state (Electron Balance; JA603N). In the next step, it was dried in a thermostat at $102 \pm 0.2{ }^{\circ} \mathrm{C}$ for 6 hours and weighed on a scale. The percentage of weight of dry matter in the leaf was calculated using the following formula [11]:

$$
A=\left(\frac{C}{B}\right) \times 100
$$

$\mathrm{A}$ is the percentage of dry matter in the leaf (\%); B is the weight of actual leaf (gm); C is the weight of dried leaf (gm) (Fig.1).
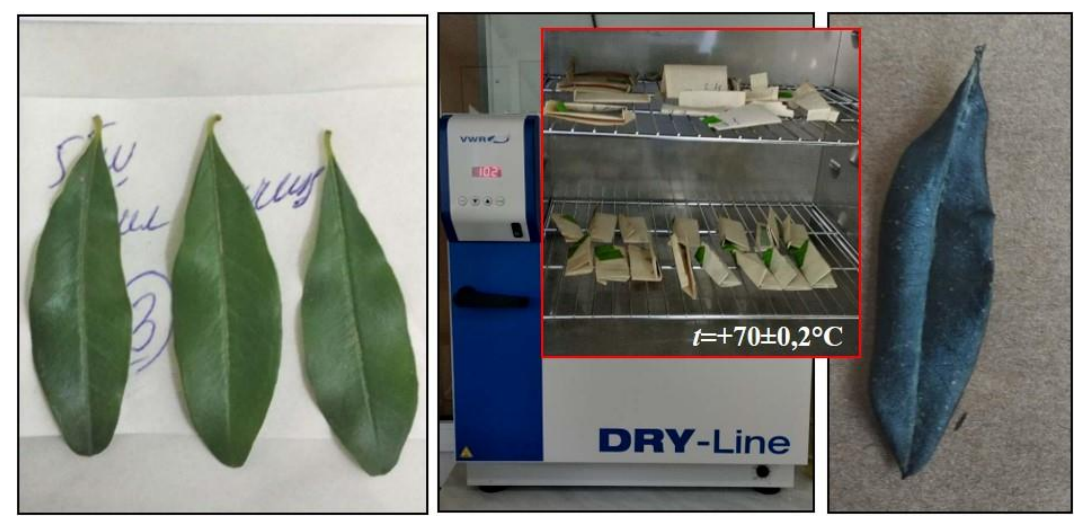

Figure 1. Pomegranate leaves used in the experimental analysis (in actual state) and after thermal treatment.

The water content in the leaf was determined by the following algorithm based on the average value of 10 leaves. Initial weight $(\mathrm{mI})$ of the leaf was determined on a scale, after drying at $5 \pm 0,1^{\circ} \mathrm{C}$ in dark condition for 2 days ( 48 hours) it weighed (mII) again. In the next step, the leaf was dried at thermostat at $102 \pm 0,2^{\circ} \mathrm{C}$ and its dried weight (mIII) was identified. Water content (MR) in the leaf was calculated using the following formula $[12 ; 13]$ :

$m_{R}=\frac{\left(m_{I}-m_{I I I}\right)}{\left(m_{I I}-m_{I I I}\right)} \times 100$ 


\section{International Journal of Agriculture, Environment and Bioresearch}

Vol. 07, No. 01; 2022

ISSN: $2456-8643$

Depending on the growing conditions, in the leaves of the pomegranate plant, the total moisture content averaged 55-58\%, and the changes during the day depending on the weather temperature were noted. The transpiration intensity in pomegranate was a maximum of $780 \mathrm{mg} / \mathrm{g}$. hours, with an average of $430-780 \mathrm{mg} / \mathrm{g}$. hours of fluctuation was recorded during the growing season. Also, the intensity of transpiration decreases with a sharp increase in air temperature in summer [3].

The specific leaf mass was determined using a standard method. The leaf was cut into pieces of the specified size $(1.55 \mathrm{~cm} 2)$ from the middle and dried in a thermostat for 6 hours at a temperature of $102 \pm 0.2^{\circ} \mathrm{C}$. The specific leaf mass was calculated using the following formula [3]:

$\rho_{\text {specific }}=\frac{m}{S}(5)$

$\rho_{\text {specific }}$ is specific leaf mass $\left(\mathrm{gm} / \mathrm{dm}^{2}\right) ; \mathrm{m}$ is weight of the cut leaf piece $(\mathrm{gm})$; Sis surface of the cut leaf piece $\left(\mathrm{dm}^{2}\right)$.

\section{RESULTS AND DISCUSSION}

It was found that the transpiration process was significantly changed when transplanting into the ground the seedlings of local pomegranate varieties obtained by in vitro microcloning. Table 1 shows the results obtained on the percentage of dry matter per day in the leaves of in vitro grown seedlings of some local varieties of pomegranate ("Qora qayim", "Qizil anor", "Oq dona (Tuya tish)" and "Achchiq dona") (Tabl. 1).

Percentage of dry matter in the leaves of "Qora qayim" and "Qizil anor" varieties were noted to decrease reliably by $29.2 \%$ and $26.7 \%$ respectively compared to control variant. It was found that the proportion of dry matter in the leaves of in vitro grown seedlings of the pomegranate varieties "Oq dona (Tuyatish)" and "Achchiq dona" decreased unreliably by $8.96 \%$ and $18.5 \%$, respectively compared to control variant (Tabl. 1).

Table 1.The results of a comparative analysis of the amount of dry matter in the leaves of the studied pomegranate varieties

\begin{tabular}{|l|l|l|c|}
\hline \multirow{2}{*}{$\#$} & \multirow{2}{*}{ Pomegranate varieties } & \multicolumn{2}{|l|}{ Percentage of dry matter in the leaf $(\%)$} \\
\cline { 3 - 4 } & & control & In vitro grown \\
\hline 1 & "Qora qayim" & $33.6 \pm 3.5$ & $23.8 \pm 3.1^{* *}$ \\
\hline 2 & "Qizil anor" & $22.5 \pm 2.4$ & $16.5 \pm 2.2^{*}$ \\
\hline 3 & "Oq dona (Tuyatish)" & $26.8 \pm 3.3$ & $24.4 \pm 2.8$ \\
\hline 4 & "Achchiq dona" & $25.4 \pm 2.7$ & $20.7 \pm 2.5$ \\
\hline
\end{tabular}

Note: $*$ - compared to control $p<0.05 ; * *-p<0.01(n=3-4)$. 
From the results obtained, it is obvious that the total dry matter content in the leaves of seedlings grown under in vitro condition was statistically significantly lower than the control. This situation is due to the mechanism of adaptation to the intensity of nutrient uptake by roots in the initial period of planting in natural soil conditions, the low content of dry matter in the leaves of in vitro grown seedlings of pomegranate can be explained by the low amount of inorganic matter in the leaves. The value of this analyzed indicator was found to be mutually different in varieties. This situation can be explained by the fact that the genetic and physiological characteristics of varieties, the degree of adaptation to soil and climatic conditions differ from each other.

In the next step of the study, the dynamics of changes were analyzed in the time interval of the percentage of dry matter in the leaves of seedlings grown under in vitro condition in the local pomegranate varieties "Qora qayim", "Qizil anor", "Oq dona (Tuyatish)" and "Achchiq dona" (Fig. 2A, B).

At the same time, it was found that in the local pomegranate varieties "Qora qayim", "Qizil anor", "Oq dona (Tuyatish)" and "Achchiq dona" no general changes were observed in the dynamics of the dry matter content change (\%) during 1-60 days. It was determined that the minimum and maximum values in the dynamics of the change in the content of dry matter in the leaves (\%) of in vitro grown seedlings of local pomegranate varieties "Qora qayim", "Qizil anor", "Oq dona (Tuyatish)" and "Achchiq dona" were respectively 23.8/30.5; 16.5/24.7; 24.4/26.7 and 20.7/23.4 during 1-60 days, i.e., increased in the form of regularity, and manifested close value to control variants within 30-60 days (Fig. 2B).
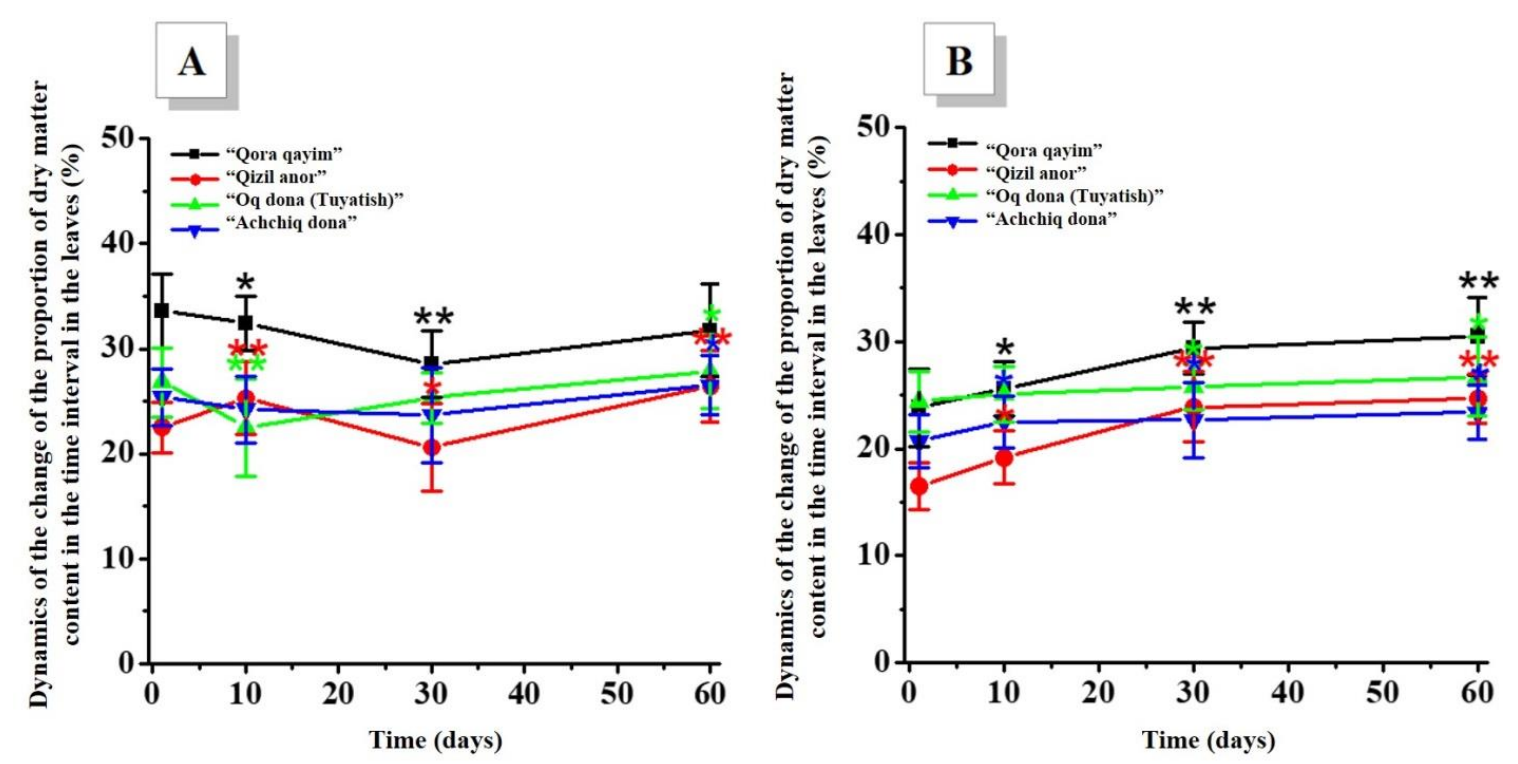

Figure2. Dynamics of the change of the proportion of dry matter content in the time interval in the leaves of seedlings of local pomegranate varieties "Qora qayim", "Qizil anor", "Oq dona (Tuyatish)" and "Achchiq dona" (A) in the leaves of in vitro seedlings (B) compared to control variant. In the ordinate axis, the percentage of dry matter in the leaf is expressed as a percentage 
$(\%)$. In the abscissa axis time is expressed (days) $*$ - compared to control $p<0.05, * *-p<0.01$ $(n=3-5)$.

The results obtained show that the mechanism of adaptation of pomegranate seedlings grown under in vitro condition to natural soil conditions occurs at high intensity during 1-30 days.

The following figures show the selected pomegranate cultivars propagated from cuttings and an overview of the in vitro seedlings of pomegranate during the growth and development (Fig.3).

\section{CONTROL}

(Pomegranate cultivars propagated from cuttings)
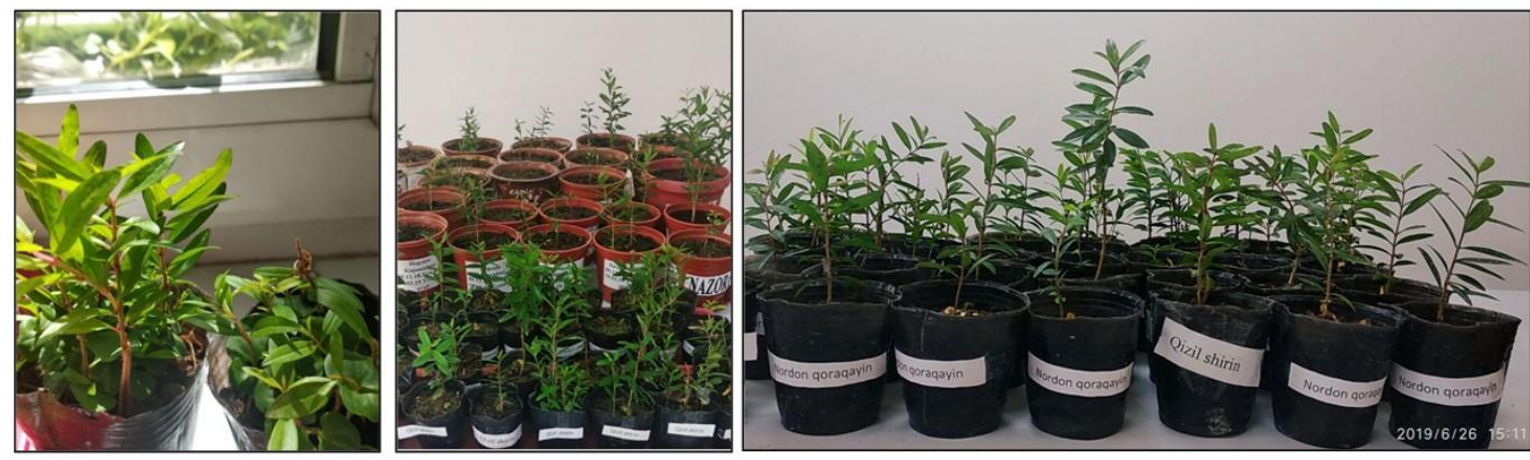

EXPERIMENT

(in vitro seedlings of pomegranate during the growth/ development)

Figure 3. Pomegranate cultivars propagated from cuttings and an overview of the in vitro seedlings of pomegranate during the growth and development.

The structure of the leaves of pomegranate seedlings propagated from cuttings of selected pomegranate varieties and in vitro grown pomegranate seedlings plays a special role in the process of photosynthesis in them[16]. In this case, the water retention parameters in the process of leaf transpiration are important in plants. So, in the next step of the experiments, the changes in water content in the leaves were analyzed when in vitro pomegranate seedlings were transplanted into natural soil (Tabl. 2).

The water content in the leaves (\%) of the control group varieties was found to be the lowest in the "Qora qayim" and the highest in the "Qizil anor" variety. It was also noted that the average water content in the leaves of local pomegranate varieties "Qora qayim", "Qizil anor", "Oq dona (Tuyatish)" and "Achchiq dona" was $72.7 \%$. The lowest value of water content in the leaves of pomegranate seedlings grown under in vitro condition was noted in the "Oq dona (Tuyatish)" variety, while the highest indicator was again observed in the "Qizil anor" variety. In vitro pomegranate seedlings manifested $78.7 \%$ water content in their leaves compared to control seedlings (Tabl. 2). 
Vol. 07, No. 01; 2022

ISSN: $2456-8643$

Table 2 The results of a comparative analysis of the amount of water in the leaves of the studied pomegranate varieties

\begin{tabular}{|l|l|l|c|}
\hline \multirow{2}{*}{$\#$} & \multirow{2}{*}{ Pomegranate varieties } & \multicolumn{2}{|l|}{ Water content in the leaf (\%) } \\
\cline { 3 - 4 } & & control & In vitro grown \\
\hline 1 & "Qora qayim" & $66.4 \pm 4.3$ & $76.2 \pm 2.5 * *$ \\
\hline 2 & "Qizil anor" & $76.5 \pm 3.2$ & $83.5 \pm 4.4$ \\
\hline 3 & "Oq dona (Tuyatish)" & $73.4 \pm 4.7$ & $75.6 \pm 3.4^{*}$ \\
\hline 4 & "Achchiq dona" & $74.6 \pm 2.4$ & $79.5 \pm 2.1^{* *}$ \\
\hline
\end{tabular}

Note: $*$ - compared to control $p<0.05, * *-p<0.01(n=3-4)$.

During the experiment of the study, the dynamics of changes of water content in the time interval was analyzed in the leaves of in vitro seedlings of local pomegranate varieties "Qora qayim", "Qizil anor", "Oq dona (Tuyatish)" and "Achchiq dona" in comparison with control variant (Fig. 3A, B).

The results of the experiment showed that no significant change in the amount of water was observed in the leaves of the selected pomegranate varieties in the control group during 1-60 days (Fig. 4A).

The water content in the leaves of in vitro seedlings decreased sharply in the first days, and in the varieties "Qora qayim", "Qizil anor", "Oq dona (Tuyatish)" and "Achchiq dona" a decrease in this value ranged from $76.2 \pm 2.5 \%$ to $52.6 \pm 3.4 \%$; from $83.5 \pm 4.4 \%$ to $62.5 \pm 2.7 \%$; from $75.6 \pm 3.4 \%$ to $58.2 \pm 2.5 \%$ and from $79.5 \pm 2.4 \%$ to $64.7 \pm 3.4 \%$ respectively within 10 days. In the next 30-60 days, the amount of water in the leaves was found to be closer to control variant, and in selected pomegranate varieties the value of this indicator increased to $65.5 \pm 3.5 ; 75.4 \pm 2.6$; $72.8 \pm 5.6$ and $73.5 \pm 3.5 \%$ in 10 days respectively (Fig. 4B).
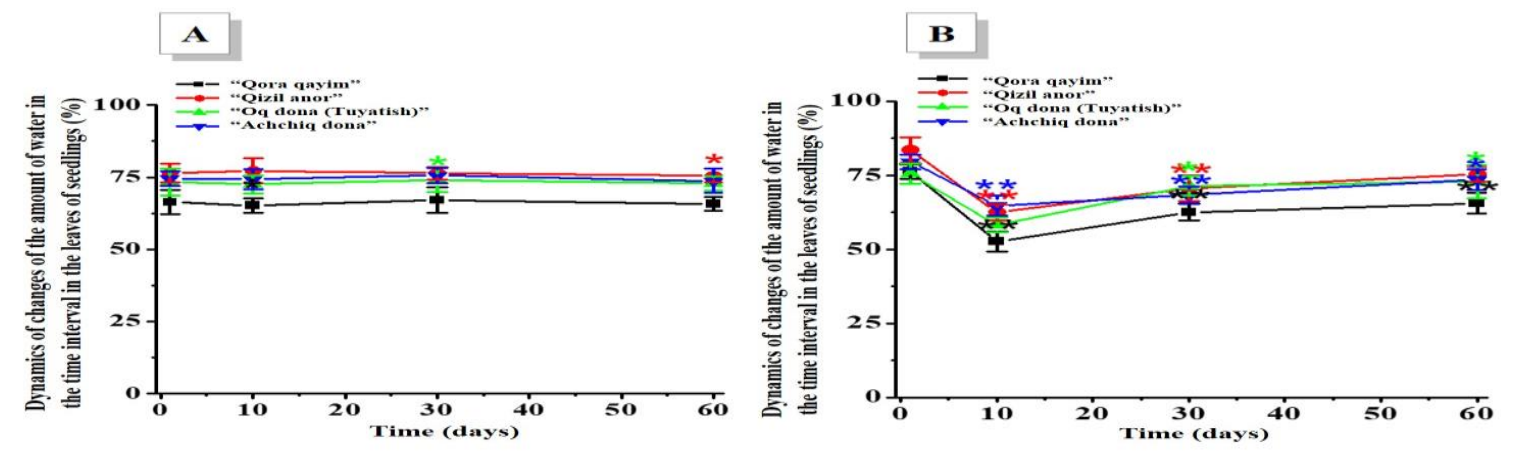

Figure 4. Dynamics of changes of the amount of water in the time interval in the leaves of seedlings (Control; A) of the local pomegranate varieties "Qora qayim", "Qizil anor", "Oq dona 
(Tuyatish)" and "Achchiq dona" and in the leaves of seedlings grown under in vitro condition (B) $(*$ - compared to control $p<0,05, * *-p<0,01 ; n=3-4)$.

The intensity of the photosynthesis process in a plant depends on the value of the specific leaf area mass. Also, the value of this indicator is an indicator that allows to estimate the intensity of transpiration in the plant $[1,22,24,25]$. Studies have shown that the specific leaf mass of pomegranate depends on the growth conditions and the developmental phases during the growing period [2].

According to the results, the specific leaf mass $(\mathrm{g} / \mathrm{dm} 2)$ of pomegranate seedlings grown under in vitro condition was statistically significantly lower than the control in the first day (1 day) (Tabl. $3)$.

Table 3 The results of the analysis of the value of the specific leaf mass of the studied pomegranate varieties

\begin{tabular}{|l|l|l|c|}
\hline \multirow{2}{*}{$\#$} & \multirow{2}{*}{ Pomegranate varieties } & \multicolumn{2}{|l|}{ Specific leaf mass $\left(\mathrm{g} / \mathrm{dm}^{2}\right)$} \\
\cline { 3 - 4 } & & control & \multicolumn{1}{l|}{ In vitro grown } \\
\hline 1 & "Qora qayim” & $0,75 \pm 0,04$ & $0,54 \pm 0,02^{* *}$ \\
\hline 2 & "Qizil anor" & $0,83 \pm 0,03$ & $0,66 \pm 0,03 * *$ \\
\hline 3 & "Oq dona (Tuyatish)" & $0,74 \pm 0,05$ & $0,62 \pm 0,04^{*}$ \\
\hline 4 & "Achchiq dona" & $0,76 \pm 0,04$ & $0,53 \pm 0,05^{* *}$ \\
\hline
\end{tabular}

Note:* - compared to control $p<0.05, * *-p<0.01(n=3-4)$.

In the control group, the value of this indicator averaged $0.77 \pm 0.04 \mathrm{~g} / \mathrm{dm}^{2}$; in the experimental group it was $0.59 \pm 0.03 \mathrm{~g} / \mathrm{dm}^{2}$. The results obtained are consistent with the results of the available literature. Typically, an increase in the value of specific leaf area mass during the plant development phase is noted to decrease with increasing moisture level [2,22,24].

In the results obtained, lower specific leaf mass $\left(\mathrm{g} / \mathrm{dm}^{2}\right)$ of pomegranate seedlings grown under in vitro condition than in the control is explained by the high content of water in the leaf during the initial period of adaptation to natural soil conditions. In order to clarify the physiological mechanism of this condition, the intensity of transpiration in the leaves was analyzed in the transfer of in vitro seedlings of local pomegranate varieties "Qora qayim", "Qizil anor", "Oq dona (Tuyatish)" and "Achchiq dona" into natural soil.

Transpiration is an integral indicator of the water regime in the plant $[3,23,24]$. It is important to study the effect of water-related stress on the transfer of a plant propagated under in vitro condition into a non-sterile soil environment [4]. Therefore, it is expedient to investigate thoroughly the water exchange, the dynamics of changes in water content in the leaves and the 
intensity of transpiration when transplanting in vitro propagated pomegranate seedlings into natural soil conditions.

It was found that the transpiration intensity was relatively high in the early stages of the adaptation period when transplanting a plant propagated under in vitro condition into a nonsterile soil environment, as well as a decrease in water content in the leaves was observed, and accordingly, it is recommended to increase the humidity level in the atmospheric environment around the plant to $90-95 \%$ and then gradually reduce it to $50 \%$ in order to ensure optimal adaptation mechanisms of the plant to soil conditions $[5,17]$.

When transplanting pomegranate seedlings grown under in vitro method into non-sterile soil, it is recommended to ensure that the humidity level of the environment is relatively high in the initial period. The above results can be used in the development of a comprehensive system of measurements to optimize the growth of in vitro grown pomegranate seedlings in the natural environment.

The experiments are a continuation of a wide range of research in this area, which allows to propagate local pomegranate (Punica granatum $\mathrm{L}$.) varieties by micro-cloning and optimize the process of obtaining pathogen-free planting material [18, 19, 20, 21].

\section{CONCLUSION}

So, the specific leaf mass $\left(\mathrm{g} / \mathrm{dm}^{2}\right)$ of pomegranate seedlings grown in vitro method was found to be low in the first day (1 day), which was assumed to depend on high water content in the leaf during the initial period of adaptation to natural soil conditions. Conducted experiment showed that the transpiration intensity was relatively high in the early stages of the adaptation period when transplanting a plant propagated under in vitro condition into a non-sterile soil environment, as well as a decrease in water content in the leaves, and accordingly, it is recommended to increase the humidity level in the atmospheric environment around the plant to $\sim 90-95 \%$ and then gradually reduce it to $50 \%$ in order to ensure optimal adaptation mechanisms of the plant to soil conditions.

\section{Acknowledgements}

Authors are grateful to the Institute of Genetics and Plants Experimental Biology, Academy of Sciences of Uzbekistan for providing space and resources to carry out this work.

\section{Authors' contributions}

All authors collaborated in the writing and editing of the manuscript.

\section{Conflict of interests}

The authors declare no conflict of interest.

\section{REFERENCES}

1. Abdullaev Kh.A, KarimovKh.Kh. Photosynthesis index in cotton-breeding. Dushanbe. Publ."Donish". 2001; 28: 61-69. 
2. Birulina Yu.G. The role of potassium channels and gas transmitters in the regulation of vascular smooth muscle contractions during hypoxia and reoxygenation. Dissertation. Tomsk, 2016; 3: 116-118.

3. Boboev I.A. Bioecological and physiological peculiarities of Punica granatum L. and Diospyros lotus L. in the condition of Tadjikistan. Dissertation. Dushanbe. 2014; 119-124.

4. Boboev I.A, Sharipov Z.Sh, Abdullaev A, Fardeyeva M.B. Specific leaf mass ofPunica granatum L. and Diospyros lotus L. in different conditions of Tadjiistan. Bulletin of the Udmurt University (Biology. Earth sciences). 2015; 25: 141-143.

5. Bolotova A.S., Shalpikov K.T. Intensity of transpiration of introduced varieties of sweet almonds on rainfed areas of southern Kyrgyzstan. Universum: Chemistry and biology: electron. scientific journal. 2016; 1-2(20): 10-14.

6. Golovko T.K, Tabalenkovo G.N. Physiology of plants: collection of works on descriptions of laboratory work for the training of a certified specialists. 2007; 35-36.

7. Ivanov L.A. About the rapid weighing method for determining the intensity of transpiration in vivo. Botan. J. 1950; 35(12): 171-185.

8. Mushinsky O.A, Ryabina Z.N, Mushinsky N.I. Transpiration as an integral part of the water regime of plants and its study in species of the genus Populus L. Bulletin of OSU. 2007; 6: 95-99.

9. Aindongo W.V. Postharvest physiology and effects of modified atmosphere packaging and anti-browning treatment on quality of pomegranate arils and aril-sac (cv. Bhagwa). Thesis presented in partial fulfilment of the requirements for the degree of master of Sci. Food Sci. (Stellenbosch University). 2014; 111-116.

10. Caleb O.J, Mahajan P.V, Al-Said F.A, Opara U.L. Transpiration rate and quality of pomegranate arils as affected by storage conditions. CyTA - Journal of Food. 2013; 11(3): 199-207.

11. Eshghi S, Jamali B. Leaf and fruit mineral composition and quality in relation to production of malformed strawberry fruits. Hort. Environ. Biotech. 2009; 50(5): 397-400.

12. Jamali B, Bonyanpour A.R. Evaluation of adaptability potential of seven Iranian pomegranate cultivars in Southern Iran, Arsenjan region. Adv. Hort. Sci. 2017; 31(2): $97-$ 105.

13. Jamali B, Eshghi S. Salicylic acid-induced salinity redressal in hydroponically grown strawberry. Comm. Soil Sci. Plant Anal. 2015; 46: 1482-1493.

14. Lopez-Rubira V, Conesa A, Allende A, Artes F. Shelf life and overall quality of minimally processed pomegranate arils modified atmosphere packaged and treated with UV-C. Postharvest Biology and Technology. 2005; 37: 174-185.

15. Newman R.A, Lansky E.P, Block M.L. Pomegranate: The most medicinal fruit. Basic Health Publication (Laguna Beach, CA). 2007: 1-120.

16. Singh S.K, Singh A, Singh N.V, Ramajayam D. Pomegranate tissue culture and biotechnology. Fruit, Vegetable and Cereal Science and Biotechnology. 2010; 4(2): 35-44.

17. Ergasheva F.Sh, Khushmatov Sh.S, Kushiev Kh.H. Water content and chlorophyll quantities in the leaves of pomegranate tree (Punica granatum L.) and their correlation. Plant Cell Biotechnology and Molecular Biology. 2021; 22(19\&20): 14-21.

18. Ergasheva F.Sh, Kushiev Kh.Kh, Matchanov A.D, Ishimov U.T, Khushmatov Sh.S. Chemical analysis of pomegranate (Punica granatum L.) fruit and peel's extract. Materials 
of the International Conference «Scientific research of the SCO countries: synergy and integration». Reports in English. Part 1. (March 26, 2019. Beijing, PRC): 85-88.

19. Ergasheva F.Sh, Kushiev Kh.Kh, Khushmatov Sh.S, Matchanov A.D. Analysis chemical composition and relaxant effects of extract of fruit peel of some local varieties of pomegranate (Punica L.). Congress Abstract Book «1 ${ }^{\text {st }}$ International Congress of The Turkic World on Health and Natural Sciences». Kyrgyzstan-Turkey (Osh/Kyrgyzstan). $2019 ; 45$.

20. Ergasheva F.Sh, Sherbaeva M.Q, Khushmatov Sh.S, Kushiev Kh.Kh. Preserving of samples of pomegranate sorts in vitro conditions. European science review («East West» Association for Advanced Studies and Higher Education GmbH. Vienna, Austria). 2018; 9-10(1): 61-66.

21. Ergasheva F.Sh., Kushiev Kh.Kh., Matchanov A.D., Ishimov U.T., Khushmatov Sh.S., Pozilov K.M. Identification of chemical content of fruit and peel's extract of some varieties of pomegranate (Punica granatum L.). Int. J. Curr. Microbiol and App. Sci. 2019; 8(5): 734-742.

22. Shavkiev J.Sh., Khamdullayev Sh.A., Nabiev S.M., Bozorov T.A., Abdishukirova S.K. Chlorophyll content in leaves of cotton varieties under the conditions of optimal irrigation regime and drought. The Way of Science. 2017; 38 (4): 16-18.

23. Shavkiev J, Nabiev S, Azimov A, Khamdullaev S, Amanov B, Matniyazova H, Nurmetov K. Correlation coefficients between physiology, biochemistry, common economic traits and yield of cotton cultivars under full and deficit irrigated conditions. Journal of Critical Review. 2020;7(4):131-136.

24. Shavkiev J, Nabiev S, Khamdullaev Sh, Usmanov R, Chorshanbiev N. Physiologicbiochemical and yield traits parameters of cotton varieties under different water irrigated regimes. Bull. Agrarian Sci. Uzbekistan 2019; 78(4(2)): 157-162.

25. N N Sanaev, N G Gurbanova, A A Azimov, T N Norberdiev, J Sh Shavkiev Inheritance of the "plant shape" trait of the varieties and introgressive lines of G. Hirsutum L. In drought conditions. Plant Cell Biotechnology and Molecular Biology 22 (25-26), 122-129. 